Check for updates

London

Cite this as: $B M J$ 2020;371:m4594 http://dx.doi.org/10.1136/bmj.m4594 Published: 25 November 2020

\title{
Covid-19: Government was too slow to respond to ventilator shortages, say MPs
}

\section{Adrian O'Dowd}

The NHS managed to provide care for all patients affected by covid-19 who needed ventilators earlier this year despite the government being

underprepared and slow in responding to hospitals' needs, MPs have said.

Good luck rather than design helped the NHS to care for patients with covid-19, none of whom were denied access to a ventilator when needed, a report from the parliamentary Public Accounts Committee has concluded.

The report, published on 25 November, praises the hard work, collaboration, and commitment of workers throughout the public sector and UK industry in responding to the pandemic from March to early August. But it criticises the government for effectively losing a vital month because it was "underprepared and reacted slowly" to the shortage of mechanical ventilators.

From March to early August the Department of Health and Social Care (DHSC) and the Cabinet Office secured an additional 26000 mechanical ventilators for use throughout the NHS at a total cost of $£ 569 \mathrm{~m}$ (€638m; \$758m), the MPs' inquiry found.

However, the government had had no plan in place before the pandemic to source the additional critical care equipment that would be needed in an emergency. The report said that both government departments prioritised speed over cost and took more risks than normal but that the approach had worked in this situation.

\section{Ventilator targets}

NHS England and NHS Improvement did not know how many ventilators the NHS already had, said the report's authors, who sought this information from individual NHS trusts in late February and found that the NHS had around 7400 ventilators-far fewer than the 59 ooo they feared might be needed. The DHSC began its initial efforts to buy more ventilators on 3 March, about a month after the pandemic emergency was announced.

The report details how the official estimates of how many ventilators the NHS would need changed repeatedly over the months. In the middle of April-considered to be the peak of hospital admissions with covid-19-the department set targets of 18 ooo ventilators by 30 April and of 30000 by 30 June to prepare for a potential second wave of the pandemic. Both of those targets were missed, said MPs, but the 30 ooo target was eventually reached by 3 August.

The committee said it was fortunate that the majority of the ventilators had not been needed and that additional capacity was now available if required.
But it voiced concern that the government's targets were not effectively calibrated to need and were not met.

\section{Future plans}

The MPs recommended that the DHSC and NHS England and NHS Improvement should set out how future emergency response plans would deal with maintaining an adequate asset register of critical equipment and a method for quickly gathering current data, as well as protocols for rapid procurement of critical equipment and the need for surge capacity in NHS supply chains.

Meg Hillier, committee chair, said, "The huge success, ultimately, of ensuring that no NHS patient who needed access to a ventilator was denied it, should not be downplayed.

"But there is a strong sense that this came about much more by luck than design, and in fact it's clear there was no design-DHSC incredibly had no plan for sourcing critical care equipment in an international emergency.

"It relied at first on an overseas market that was under great pressure and seeing prices increase exponentially because of the international nature of the pandemic. DHSC didn't know what equipment hospitals already had, and its estimates of need fluctuated considerably as the pandemic progressed."

A DHSC spokesperson commented, "Throughout this global pandemic we have done whatever it takes to protect the NHS and save lives, including ensuring everyone who needed a ventilator had access to one.

"As the recent National Audit Office report states, the government acted quickly to secure the ventilators it thought were needed to safeguard public health and maintained sufficient record of the programmes' rationale and key spending decisions.”

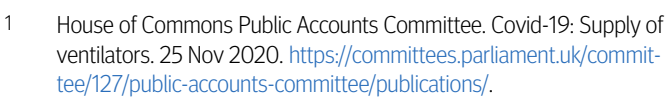

This article is made freely available for use in accordance with BMJ's website terms and conditions for the duration of the covid-19 pandemic or until otherwise determined by BMJ. You may use, download and print the article for any lawful, non-commercial purpose (including text and data mining) provided that all copyright notices and trade marks are retained. 